\title{
Lady's mantle (Alchemilla vulgaris L., Rosaceae): A review of traditional uses, phytochemical profile, and biological properties
}

\author{
VAnja Tadić ${ }^{1, *}$, Nemanja Krgović ${ }^{1}$, ANd AnA Žugić ${ }^{1}$ \\ ${ }^{1}$ Institute for Medicinal Plants Research "Dr. Josif Pančić", Tadeuša Košćuška 1, 11000 Belgrade, Serbia \\ *Corresponding author:vtadic@mocbilja.rs
}

Received: November 11, 2020

Accepted: December 20, 2020

Published on-line: December 22, 2019

Published: December 25, 2020

\begin{abstract}
Lady's mantle (Alchemilla vulgaris L. syn. Alchemilla xanthochlora Rothm., Rosaceae) has been commonly used in folk medicine to heal inflammations in the mouth, bleeding of the nose, furuncules, gynaecological (menorrhagia and dysmenorrhoea), and gastrointestinal disorders. Although therapeutic indications for lady's mantle are non-specific diarrhoea and gastrointestinal complaints, it has been reported to exert, as well, a variety of biological activities, including wound healing, antimicrobial, neuroprotective, gastroprotective, cytotoxic, and antioxidant. Lady's mantle presents a valuable source of natural bioactive compounds, mostly phenolic compounds - a large amount of tannins, phenolcarboxylic acids, and flavonoids, being responsible for the abovementioned effects. In this work, a literature review of biological properties, investigated in in vitro and in vivo experiments in regard to the determined chemical profile is presented. In addition, the data reported are discussed, and the directions for further investigations are proposed.
\end{abstract}

Key words: Alchemilla vulgaris, lady's mantle; phytochemical profile; traditional application; biological properties

\section{INTRODUCTION}

In the last ten years, two revolutionary changes occurred in classical medicine, which have great implications on the research both in phytomedicine and natural products chemistry. The first change can be described as a gradual withdrawal from the dogma of mono-substance therapy and an increasing transition to the treatment of patients with drug combinations. We call this therapy multidrug therapy. The second can be characterized as a transition to a new kind of multitarget therapy, which is directed primarily toward the activation of defense, protective, and repair mechanisms of the body rather than toward the direct destruction of the damaging agents (e.g. the tumor cell or the pathogenic microorganism). Phytomedicine research has a good chance of contributing to these new strategies through the development of new and better drugs for evidence-based and rational therapy. Namely, phytotherapy has long followed and developed these strategies by using mono-extracts or extract combinations containing mixtures of bioactive compounds and by activating primarily self-healing and protective processes of the human body, rather than attacking and directly destroying the damaging agents (Tadić et al., 2014).

Medicinal plants have been recognized as an inexhaustible source of bioactive compounds which have been used since ancient times for the treatment of many diseases. Herbal medicinal products as potential therapeutic agents are becoming increasingly important in pharmacy and have great popularity from the perspective of the general public who perceive medicinal plants as a good alternative to the single chemical entity medicines application. The benefit of using herbal medicinal products for a particular illness is because they contain a complex of active components with polypharmacological action and synergistic effects (Gibbons, 2003). In this contest, of great importance is to make a review of up to date performed investigations on medicinal plants traditionally used in the treatment of different health impairments.

One of these plants, that have medicinal quality to provide the rational means for the treatment of many diseases, is Alchemilla vulgaris L. syn. Alchemilla xanthochlora Rothm., commonly known as lady's mantle and bear's foot, well-known species from the genus Alchemilla (Rosaceae). The genus Alchemilla includes about 250 species growing on wet meadows in Europe, western Asia, and North America (Evans and Evans, 2009; Duckstein et al., 2012). In Serbia, lady's mantle is presented with three subspecies (subsp. montana, subsp. pratensis and subsp. vulgaris) (Vlaisavljević et al., 2019). According to the phytochemical studies, the aerial part of the plant contains mostly phenolic compounds - a large amount of tannins (el- 
lagitannins, the main one is agrimoniin), phenolcarboxylic acids (ellagic, gallic and caffeic acid) and flavonoids (quercetin and kaempferol, and their glycosides) (Shilova et al., 2020).

ESCOP Monographs described lady's mantle usage for nonspecific diarrhoea, gastrointestinal disorders, and dysmenorrhea based on human experience and long-standing use (Özbilgin et al., 2019; Blumental et al., 1998; ESCOP, 2003; Hager, 1979; Tucakov, 1997). Lady's mantle is traditionally used due to its tannin content for the treatment of inflammation of the upper digestive tract and diarrhoea internally, as a woundhealing agent and astringent externally, and as gargle against mouth and throat inflammation. In Bulgaria, it is used to heal inflammations in the mouth, bleeding of the nose, furuncules, and gynecological diseases, while in Poland is used as an antiinflammatory, carminative and anti-diarrheal remedy, and against gastritis. It is also reported that the aerial parts of this plant are used traditionally in Montenegro, internally to treat mild and nonspecific diarrhoea, menopausal complaints, and dysmenorrhea, and against ulcers, eczema, and skin rashes externally (Ergene et al., 2010). Other Alchemilla species are also used as a diuretic, in the treatment of liver inflammation, asthma, bronchitis, cough, and diabetes, as well as kidney, intestinal, and gastric disorders (Özbilgin et al., 2019). In this paper, several most important biological effects of lady's mantle extracts will be presented in relation to the determined phytochemical profile.

\section{PHYTOCHEMICAL ANALYSIS OF LADY'S MANTLE}

Rational phytotherapy is a modern form of phytotherapy that involves the treatment and prevention of diseases and health impairments by applying herbal medicinal products based on standardized extracts with clinically proven therapeutic efficacy (Petrović, 2019). In standardized extracts, the active constituents (single or groups) responsible for the assessed biological activities should be determined (Heinrich et al., 2012). Hence, taking into account the principle of modern phytotherapy, qualitative and quantitative analysis of plant extracts are necessary to be performed. Due to the growing development of new methods, the chemical analysis enabled the elucidation of the molecular structure of secondary metabolites, at the same time providing the identification or confirmation of the structural identity of a chemical compound(s) responsible for the evaluated biological activity. Generally, the presence of different types of polyphenol compounds in the plant materials well correlates with numerous biological activities. Therefore, according to the results presented in previous studies on the chemical composition of various lady's mantle extracts, the major identified components which might be responsible for the biological effects presented in this review were given in Figure 1.

\section{BIOLOGICAL EFFECTS OF LADY'S MANTLE}

\subsection{Wound healing}

Human skin is permanently exposed to the external atmosphere and is therefore easily prone to injury. However, it has a natural ability to promote the self-regeneration after damage, achieved through a complex biological process comprising several overlapping biochemical and cellular phases. In this context, investigations of the potential of medicinal plants to accelerate wound healing may be especially applicable, due to their multi-component nature hence providing several biological activities, such as antioxidant, anti-inflammatory, antimicrobial, and cell-stimulating properties, relevant to wound healing management. The traditional usage of lady's mantle in wound healing has been confirmed in several recent scientific studies (Choi et al., 2018; Tasić-Kostov et al., 2019).
In one of our previous papers, several extracts of lady's mantle aerial part were prepared by maceration with various solvents (water, ethanol, and propylene glycol). Thereafter, stated extracts have been investigated for wound healing in the in vitro scratch assay using L929 fibroblasts. With the idea of not only the scientific justification of the traditional usage, but also the correlation of wound healing activity to the chemical composition of the investigated extracts, this study revealed macerate prepared with ethanol to be the most abundant in total phenolic, total flavonoid, and total tannins content and at the same time to possess the strongest antioxidant activity as well as the most pronounced effect of fibroblasts migration and the highest extent of wound closure. Hence, the wound healing of lady's mantle extracts was attributed to phenolic compounds and their antioxidant activity. Further assessed HPLC analysis (Figure 2) confirmed the presence of different polyphenols (ferulic acid (1), rutin (2), hyperoside (3), ellagic acid (4), isoquercetin (5), luteolin-7-O-glucoside (6), kaempferol-3-O-glucoside (7), apigenin-7-O-glucoside (8), luteolin (9), kaempferol (10), morin (11), quercetin (12) and tiliroside (13)), with ellagic acid, isoquercetin and morin being most abundant (the quantity varied from 1.9 to $6.5 \mathrm{mg} / \mathrm{g}$ dry extract in the investigated samples). These three phenolic compounds (ellagic acid, isoquercetin, and morin) were detected in all investigated extracts, indicating their high content to be partly responsible for the observed wound healing properties of the extracts (Tasić-Kostov et al., 2019). Indeed, a recent study revealed ellagic acid (4) to be able to prevent collagen destruction and inflammatory responses caused by UV-B light, in addition to previously reported prevention of cutaneous lipid peroxidation, thus improving collagen production and subsequently increasing the speed of healing (Amadeu et al., 2003; Bae et al., 2010; Jimenez et al., 2006; Singer and Clark, 1999). In this connection, Ilić-Stojanović et al. (2018) recently reported the development of stimulus-sensitive hydrogels, which are used as carriers for modified release of ellagic acid from lady's mantle extract. Aside from ellagic acid, another compound found in lady's mantle, quercetin-3-O- $\beta$-glucuronide (14) was reported to stimulate collagen synthesis. Namely, the activity of this compound as a collagenase inhibitor was higher than doxycycline, a Federal Drug Administration (FDA)-approved drug, used as a positive control in this study. It might be added that aside from wound or burn healing, collagenase inhibitors might be useful in the treatment of other skin-related diseases, such as dermatitis, acne, urticarial, or photoaging (Mandrone et al., 2018). Also, Vlaisavljević et al. (2019) revealed amylase and tyrosinase inhibitory effects of $A$. vulgaris, which might be related to antidiabetic and skin-related diseases (Vlaisavljević et al., 2019). Improvement of wound healing of lady's mantle was also connected to its anti-inflammatory effects (Ghedira et al., 2012), which were recently confirmed in the study of Boroja et al. (2018) where a methanolic extract of aerial part of this plant (in the concentration of $50 \mu \mathrm{g} / \mathrm{mL}$ ) was shown to inhibit the activity of COX-1 enzyme by $44.4 \%$, whereas the inhibition of COX-2 was higher (63.6 \%) (Boroja et al., 2018).

Aside from the papers dealing with the wound healing properties of the extracts of lady's mantle, several papers dealt with the stated activity of topical formulations containing extracts of this plant as active principles. For instance, Choi et al. (2018) showed that the application of an ointment containing the herbal mixture of lady's mantle and Mimosa tenuiflora (mimosa), another plant traditionally used to treat cutaneous wounds, on the dorsal skin wounds of mice led to the faster healing process compared to conventionally used ointment with fusidic acid, used as control. Further assessed histological investigation revealed the mixture to promote reepithelialization, collagen synthesis, and regeneration of skin appendages, while immunohistochemical analysis indicated 

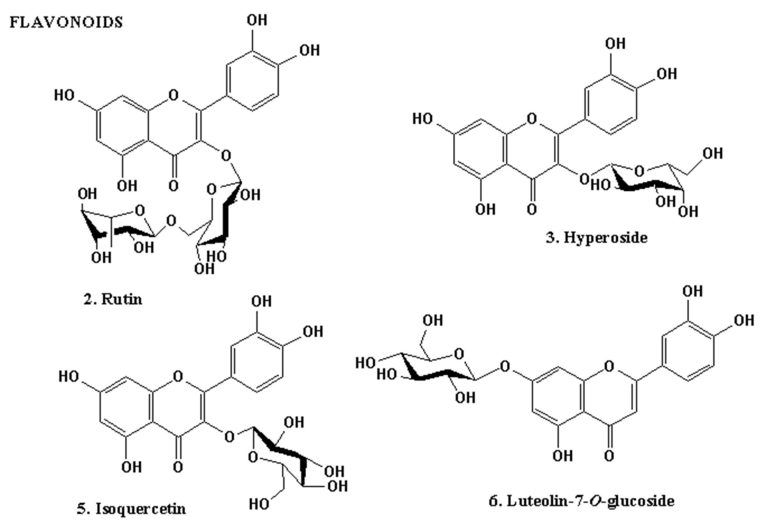<smiles></smiles>

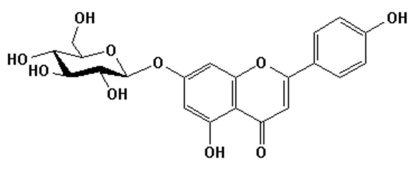

7. Kaempferol-3-a-glucoside<smiles>O=c1cc(-c2ccc(O)c(O)c2)oc2cc(O)cc(O)c12</smiles><smiles>O=c1c(O)c(-c2ccccc2)oc2cc(O)cc(O)c12</smiles><smiles></smiles><smiles></smiles><smiles>COC(=O)c1c(-c2ccc(O)c(O)c2)oc2cc(O)cc(O)c2c1=O</smiles><smiles>O=C(O)C1CCCCC1(O)OCCOc1c(-c2ccc(O)c(O)c2)oc2cc(O)cc(O)c2c1=O</smiles><smiles>O=c1c(-c2ccc(O)cc2)coc2cc(O)cc(O)c12</smiles><smiles>O=c1cc(-c2ccc(O)cc2)oc2cc(O)cc(O)c12</smiles>

SIMPLE PHENOLS<smiles>O=C(O)c1cc(O)c(O)c(O)c1</smiles><smiles>OCC(O)C(O)C(O)COc1ccc(O)cc1</smiles>

PHENOLCARBOXYLIC ACIDS<smiles>COc1cc(/C=C/C(=O)O)ccc1O</smiles>

21. Sinapic acid<smiles>O=C(O)/C=C/c1ccc(O)c(O)c1</smiles><smiles>O=C(O)/C=C/c1ccc(O)cc1</smiles><smiles>O=C(/C=C\c1ccc(O)c(O)c1)O[C@H]1C[C@@H](O)[C@@H](O)[C@H](O)[C@H]1C(=O)O</smiles>

COUMARINS<smiles>O=c1ccc2ccc(O)cc2o1</smiles>

23. Umbelliferone<smiles>O=c1ccc2cc(O)c(O)cc2o1</smiles>

24. Esculetin

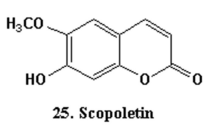

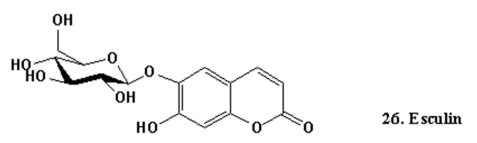

TANINS



PROCYANIDIN TYPE COMPOUNDS

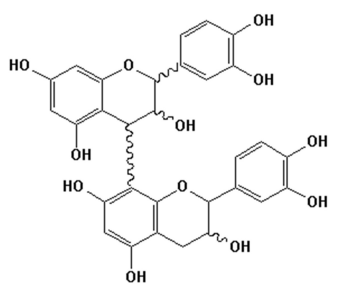

28. Procyanidin type

Fig. 1. Secondary metabolites identified in lady's mantle (A. vulgaris L., Rosaceae) extracts investigated in the literature cited in the review

improvement of angiogenesis and stabilization of blood vessels, as well as the acceleration of the formation of granulation tissue. Also, the herbal mixture enhanced the migration of HaCaT, fibroblasts, and HUVECs on a two-dimensional wound model, and also promoted the proliferation of macrophages and lymphatic vessels (Choi et al., 2018). Similarly, TasićKostov et al. (2019) investigated topical preparations (gels) containing the extracts of lady's mantle aerial parts as active principles for wound healing using the in vitro scratch assay, complemented by the in vivo test of barrier repairment of the skin after skin damage induced using the detergent sodium lauryl sulfate (SLS). Although there were no significant differences between gels containing macerates of A. vulgaris aerial parts prepared with various solvents (water, ethanol, and propylene glycol) in the in vitro wound closure, the most prominent effect was observed in the case of the gel with propylene glycol extract. Further assessed in vivo study revealed an increase of transepidermal water loss (TEWL), as the measure of skin barrier repairment, accompanied by the growth of stratum corneum hydration after 7-day treatment with all investigated 


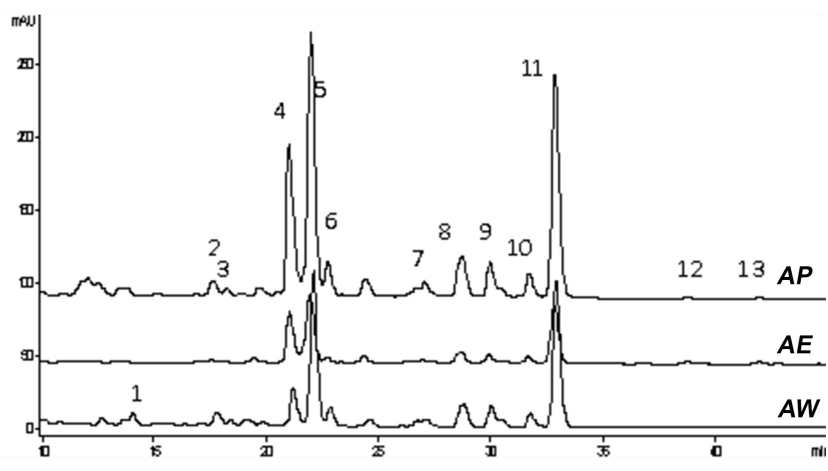

Fig. 2. Comparative HPLC hromatograms of propylene glycolic (AP), ethanolic (AE) and water (AW) extracts of A. vulgaris (the numbers asigned to peaks correspond to compounds presented in Figure 1)

gels with lady's mantle extracts. Such findings suggested hydrogels to be adequate vehicles for wound dressings on the one hand, and indicated topical application of gels with lady's mantle extracts, regardless of the extraction solvent, to induce the epithelial cell growth, thus promoting the wound healing process, on the other (Tasić-Kostov et al., 2019).

In a similar experimental setup (in vivo investigation of the effects on SLS-irritated skin), cream with the extract of lady's mantle in the concentration of $1.5 \%$ was reported to provide the best anti-inflammatory effect, among several creams with the same action in different concentrations $(1 \%, 1.5 \%, 2 \%$, and $3 \%$ ). Namely, this concentration of the extract in a semisolid vehicle, after its seven-day application on artificially irritated skin, led to the decrease of irritation i.e. recurrence of erythema index (EI) to the level before irritation. In comparison, cream with $1 \%$ of the extract led to recurrence of EI to initially accessed values (before irritation) only after nine days of application. In addition, the increase of the extract concentration from $1.5 \%$ to $2 \%$ or $3 \%$ did not cause an increase in the anti-inflammatory potential of the corresponding creams. Chemical analysis of the lady's mantle extracts incorporated into the tested creams revealed the presence of tannins (not less than $3.5 \%$ ), while further accessed HPLC analysis identified three major flavonoids to be isoquercetin (5), luteolin-7-Oglucoside (6), and quercetin (12). Thereafter, the authors connected the chemical composition of the extracts to the exerted anti-inflammatory effect of the investigated creams. Namely, quercetin and isoquercetin were previously shown to inhibit both acute and chronic phases of inflammation, to possess COX and lipoxygenase (LOX) inhibitory activities, and were effective in the treatment of allergic reactions. In addition, they are probably included in the inhibition of the production and the release of histamine. On the other hand, biological effects of tannins in animal and human cells and tissues are related to their ability to chemically react with proteins and build insoluble complexes, which is manifested in the precipitation of proteins in the surface layers (astringent effect). In addition, all identified compounds in the extract were shown to have a pronounced antioxidant effect (Žižović et al., 2016).

\subsection{Antioxidant activity}

Lately, a number of diseases such as Parkinson's disease, cancer, cardiovascular, and obesity-related diseases have been connected to oxidative stress, therefore underlining many scientific reports investigations of antioxidative activity of different compounds, and in particular the ones of plant origin. In this connection, several authors reported strong antioxidant activity of lady's mantle (ESCOP, 2003), but only the most recent ones will be presented in this review.

In the investigation of (Boroja et al., 2018) different assays were performed in order to compare the antioxidative potential of the methanolic extracts of aerial parts and roots of lady's mantle. The results of this study pointed to significantly better $(\mathrm{P}<0.05)$ antioxidant activity of the extracts prepared from the aerial parts compared to the roots in all employed methods, except for total antioxidant activity. Nevertheless, the potential of the extract obtained from the aerial parts of the plant to neutralize free radicals $\left(\mathrm{DPPH}^{\bullet}, \mathrm{ABTS}^{\bullet+}\right.$, and $\left.{ }^{\bullet} \mathrm{OH}\right)$ was significantly lower $(\mathrm{P}<0.05)$ compared to the synthetic antioxidant butylated hydroxytoluene (BHT), while there was no statistically significant difference compared to catechin. It should be emphasized that particularly better antioxidant activity in the inhibition of lipid peroxidation was observed for this extract compared to the one prepared from the roots of lady's mantle. Such results were ascribed to the high amount of polyphenols in the tested extract, where in the one obtained from Alchemillae herba the major identified compound was ellagic acid (Boroja et al., 2018).

Similarly, Vlaisavljević et al. (2019) used several antioxidant assays (DPPH, ABTS, CUPRAC, phosphomolybdenum, metal chelating, FRAP) to compare the antioxidant potential of methanolic, ethanolic, ethyl-acetate, and water extracts of lady's mantle. The authors found a strong correlation between total phenolic content and antioxidant activity, with ethyl-acetate extract having the highest content of total phenol compounds (9.65 mg GAE/g) and therefore the highest antioxidant activity. In general, the most pronounced and significant antioxidant effects of tested extracts were observed for DPPH and FRAP assays, where the best activity of the ethyl-acetate extract was followed by methanolic and water extract, which revealed significantly lower anti-radical activity compared to the other extracts (Vlaisavljević et al., 2019). Antioxidative effects of macerates of Alchemillae herba prepared with water, ethanol, and propylene glycol were recently confirmed in $\mathrm{DPPH}$ and $\beta$-Carotene-linoleic acid assay. The activity of the ethanolic extract was determined to be much higher than two other extracts in DPPH test, which was in line with the highest amount of total phenols, total flavonoids, and total tannins in this extract; however, exerted antioxidant potential was much weaker compared to the reference antioxidants (BHT and BHA) (Choi et al., 2018; Tasić-Kostov et al., 2019).

\subsection{Treatment of dysmenorrhoea}

The application of the aerial parts of lady's mantle in dysmenorrhea, which is recommended by its ESCOP monograph, is in line with its traditional utilization against pruritus vulvae, bleeding from the uterus, and menstrual pains (ESCOP, 2003; Vlaisavljević et al., 2019).

Recently, a study by Vlaisavljević et al. (2019) suggested that the use of the plant in traditional medicine for woman related diseases might be scientifically justified due to hormonedependent anticancer activity (breast and ovarian anticancer effects) observed for several lady's mantle extracts. Namely, in this study cytotoxic effects of methanolic, ethanolic, ethylacetate, and water extracts of lady's mantle from Southeast Serbia (central Balkan) was investigated against several cancer cell lines, including invasive cancer lines resistant to conventional chemotherapeutics, such as human breast MCF7 and ovarian A2780 cancer cells. The results of this study revealed that ethyl-acetate extract generally had the strongest potential to decrease tumor cells' viability. Also, ovarian A2780 and breast carcinoma MCF7 displayed a better response to treatment with methanolic extract compared to the ethanolic one. Different efficacy of used lady's mantle extracts against tested cell lines in this study might be connected to their different chemical composition, especially when it comes to substances with proven anticancer activity. For instance, caffeic (15) and gallic acid (16), determined to be present only in the ethyl- 
acetate extract, were previously shown to possess strong antiproliferative and cytotoxic properties in a wide range of tumor types such as those used in this study. Stated effects of these phenolic acids were achieved through several mechanisms such as interference with main signaling pathways involved in cell cycle progression and cell death, then interference with migrative and invasive properties, epithelial/mesenchymal transition, and angiogenesis, as well as the ability to sensitize tumor cells to conventional therapeutics. Aside from these components, genistein (17), protein tyrosine kinase inhibitor, and quercetin (12), which were also present only in the ethylacetate extract, were reported to display strong anticancer potential through inhibition of cell cycle progression, induction of apoptosis, affecting MAP-ERK signaling pathway, inhibiting the metastatic properties of malignant cells (Vlaisavljević et al., 2019).

\subsection{Neuroprotective activity}

Various central nervous system (CNS) disorders including neurodegenerative diseases, stroke, and trauma can be caused by different biochemical reactions and substantial processes, such as protein aggregation, reactions of free radicals, insufficient blood supply, glutamate excitotoxicity, and oxidative stress, which lead to apoptotic or necrotic cell death. Medicinal plants are widely studied for their neuroprotection activity. One of the biologically-active groups of secondary metabolites in plants are polyphenols (flavonoids, phenolic acids, tannins) which are powerful antioxidants with beneficial effects on brain health. Polyphenols have been reported to exert their neuroprotective actions through an ability to suppress neuroinflammation, to decrease oxidative stress, and to increase the expression of genes that encode antioxidant enzymes, neurotrophic factors, and cytoprotective protein (Lalkovicová and Danielisová, 2016).

Aging is the primary risk factor for most neurodegenerative diseases, including Alzheimer's and Parkinson's disease. Few or no effective treatments are available for these disorders, which tend to progress in an irreversible manner and are associated with large socioeconomic and personal costs (Hou et al., 2019). In Parkinson's disease (PD) there is selective degeneration of neuromelanin-containing neurons, especially substantia nigra dopaminergic neurons, where the loss of dopaminergic (DA) neurons therein leads to the typical motor symptoms of the disease and constitutes the cardinal pathologic diagnostic criterion for PD. The dark-brown cytoplasmic pigment neuromelanin (NM) accumulates with age and is the main risk factor for PD. It is supposed that brain tyrosinase overexpression implicates age-dependent neuromelanin production in PD pathogenesis. Therefore, inhibitors of tyrosinase may be a useful therapeutic option in the prevention of PD (Carballo-Carbajal et al., 2019). Alzheimer's disease (AD), the most common dementia type, is a progressive, irreversible neurodegenerative disease clinically characterized by cognitive and behavioral impairments. The prevalence of AD is rising and reaching epidemic proportions. It is stated that decreased cortical acetylcholine levels in dementia patients are in correlation with an increase in cognitive symptoms, and available anti-dementia medications provide only modest and transient cognitive benefits. Among them are cholinesterase inhibitors (donepezil, rivastigmine, and galantamine), which are indicated for the symptomatic management of mild to moderately severe AD (Micov and Pecikoza, 2020).

Recently performed studies gave evidence that some plants worked as acetylcholinesterase inhibitors. Shilova et al. (2020) performed an investigation of the neuroprotective properties of the infusion of lady's mantle aerial part in an experiment on animals. They evaluated the effects of the infusion after hypoxic exposure modeled by hypoxia in a hermetic chamber on the number of free radicals reacting with the stable free radical-chromogen $\mathrm{DPPH}$, the content of LPO end-metabolite thiobarbiturate-reactive products (TBA-RP), and orientationalexploratory behavior indicators of animals. Infusion of the aerial part of lady's mantle (in dose $0.5 \mathrm{~mL} / \mathrm{kg}$ ) exhibited neuroprotective properties, normalized the exploratory behavioral parameters of the animals after hypoxic exposure, reduced the contents of TBA-RP by exhibiting antioxidant properties and of antiradical antioxidants that increased as a result of LPO activation in brain tissues due to oxidative stress caused by hypoxic shock. Neuroprotective properties of lady's mantle infusion were probably due to phenolic constituents (simple phenols - arbutin (18), flavonoids - rutin (2), hyperoside (3), luteolin-7-O-glucoside (6), astragalin (7), apigenin-7$O$-glucoside (8), luteolin (9), kaempferol (10), quercetin (12), apigenin (19), phenolcarboxylic acids - $p$-coumaric (20), sinapic (21), ferulic (1), caffeic (15), gallic (16), chlorogenic (22) ellagic (4), coumarins - umbelliferone (23), esculetin (24), scopoletin (25), esculin (26), primarily hydrolyzed tannins - ellagitannins, the main one being agrimoniin (27), up to $10 \%$ ) (Shilova et al., 2020).

The treatment of neurodegenerative disorders such as AD and $\mathrm{PD}$, include the use of acetylcholinesterase and tyrosinase inhibitors. While inhibitor of acetylcholinesterase was approved in Europe for the treatment of AD (such as galantamine, isoquinoline alkaloid isolated from the Galanthus woronowii bulbs (Bulduk et al., 2018), tyrosinase inhibition has become a popular target in drug development and research for PD. In a line with this, three different concentrations $(3 \mathrm{mg} / \mathrm{mL}, 1.5$ $\mathrm{mg} / \mathrm{mL}$, and $0.75 \mathrm{mg} / \mathrm{mL}$ ) of aqueous and $70 \%$ ethanolic extracts of lady's mantle and Filipendula ulmaria were evaluated for their acetylcholinesterase and tyrosinase inhibitory effects. The acetylcholinesterase inhibitory activity was determined to be between 77.03 and $98.39 \%$ (at the highest used dose, being $3 \mathrm{mg} / \mathrm{mL}$ ), and the tyrosinase inhibitory activity was found to be between 60.00 and $90.65 \%$ (at $3 \mathrm{mg} / \mathrm{mL}$ ) for all investigated plants extracts. The lady's mantle $70 \%$ ethanolic extracts $(3 \mathrm{mg} / \mathrm{mL})$ showed higher acetylcholinesterase inhibitory activity compared to aqueous extract $(96.50-84.86 \%$ ). The result for galantamine, positive control, was $99.98 \%$ (at $1.5 \mathrm{mg} / \mathrm{mL}$ ). In addition, $70 \%$ ethanolic extract of lady's mantle (at $3 \mathrm{mg} / \mathrm{mL}$ ) showed higher tyrosinase inhibitory activity compared to aqueous extract $(71.55-60.00 \%)$. The result for kojic acid, potent tyrosinase inhibitor was $94.2 \%$ (at $3 \mathrm{mg} / \mathrm{mL}$ ). The evaluated activities might be assigned to the presence of apigenin-7-O- $\beta$-glucoside, luteolin-7-O- $\beta$-glucoside, quercetin, and rutin, whose enzyme inhibitory activities were confirmed in earlier conducted research (Kim and Uyama, 2005; Lee et al., 2016; Si et al., 2012). Besides, it was suggested that these statistically significant differences between extracts were due to the higher content of polyphenols and proanthocyanidins (28) in ethanolic extracts (Neagu et al., 2015).

\subsection{Gastroprotective activity}

Peptic ulcer disease represents the break in the inner lining of the stomach, the first part of the small intestine, duodenum, or sometimes the lower esophagus. The lifetime prevalence of peptic ulcer disease in the general population has been estimated to be about $5-10 \%$, and incidence $0.1-0.3 \%$ per year (Lanas and Chan, 2017). The predominant symptom of uncomplicated peptic ulcer is epigastric pain, which can be accompanied by other dyspeptic symptoms such as fullness, bloating, early satiety, and nausea. The imbalance of aggressive gastric luminal factors acid and pepsin and defensive mucosal barrier function is the major mechanism in the pathogenesis of peptic ulcer. Several factors such as smoking, excessive alcohol use, drug use (especially nonsteroidal anti-inflammatory drugs, NSAID), emotional stress, and psy- 
chosocial factors contribute to ulcer formation by increasing gastric acid secretion or weakening the mucosal barrier. Moreover, epidemiological studies revealed a very strong association between Helicobacter pylori infection and duodenal and gastric ulcers (Malfertheiner et al., 2009). Treatment of peptic ulcers has been focused on mitigation of symptoms, healing ulcers, and avoiding reappearance of the ulcer. For these purposes several drugs are used, i.e. inhibitors of a proton pump (omeprazole and lansoprazole), antagonists of the $\mathrm{H} 2-$ receptor (famotidine), and antibiotics. As an alternative treatment method, herbal medicines present a source of different biologically active substances (tannins, flavonoids, alkaloids, triterpenoids, steroids, saponins, and coumarins) with antiulcerogenic activity, and their use is now considered integral to practicing a healthy lifestyle (Asnaashari et al., 2018). H. pylori and the NSAIDs are the main aggressive factors involved in the pathophysiology of gastroduodenal ulcer. ValchevaKuzmanova et al. (2019) in their study aimed to investigate the effects of four Aronia melanocarpa-based juices in a rat model of indomethacin-induced gastric ulceration. The juices were: AM1 and AM2 (produced from A. melanocarpa fruits at $20^{\circ} \mathrm{C}$ and $60^{\circ} \mathrm{C}$, respectively), AMRC (a mixture of AM2 with Rosae caninae pseudofructus extract), and AMAV (A. melanocarpa juice with Alchemillae herbae extract). The pre-treatment of rats with the four juices ameliorated the severity of the ulcer model which was demonstrated by macroscopic indices as well as by histopathological and immunohistochemical investigations. The ulcer number and ulcer area, as well as the ulcer score and ulcer index, were reduced by pretreatment of rats with juices. Juice AMAV, characterized by the highest total polyphenol content, flavonoids, and phenolic acids, showed the best gastroprotective effect. In this experiment, probably the most important mechanism underlying the gastroprotective effect of the juices was the inhibition of apoptosis. Juice AMAV antagonized the effects of indomethacin on apoptosis markers with the highest activity (Valcheva-Kuzmanova et al., 2019). In another study, Krivokuća et al. (2015) revealed strong antiHelicobacter pylori activity of different extracts of Alchemilla species, ascribing mainly the revealed effects to the presence of ellagic acid in the investigated samples (Krivokuća et al., 2015).

\subsection{Protective role in cisplatin-induced toxicity}

Cisplatin (cis-diamminedichloroplatinum-II) is a highly effective chemotherapeutic agent used in the treatment of testicular, head and neck, ovarian, cervical, and non-small-cell lung cancers, whose clinical application is limited by side effects such as nephrotoxicity, ototoxicity, and hepatotoxicity (Ojha et al., 2016; Oun et al., 2018). Tissue injury caused by cisplatin can be explained by oxidative damage, inflammatory processes, and apoptosis (Abdel-Daim et al., 2019). Natural products and phytochemicals can be used for the prevention of cisplatininduced toxicity. Based on the results of numerous studies revealing strong antioxidant capacity in vitro, the possible effect of lady's mantle methanol extracts obtained from aerial parts and roots (AVA and AVR, respectively) was evaluated in the prevention of cisplatin-induced hepatorenal and testicular toxicity in rats. Results showed that application of cisplatin decreased testosterone level and tissue's antioxidants activity (SOD - superoxide dismutase, CAT - catalase, and GSH glutathione), while it increased levels of transaminases, ALP (alkaline phosphatase), GGT (gamma-glutamyl transferase), urea, uric acid, creatinine and TBARS (thiobarbituric acid reactive substances). Treatments with AVA and AVR significantly decreased the levels of serum parameters of the liver (total bilirubin and ALP) and kidneys (urea and creatinine), and improved enzyme antioxidant activity, while the impact of extracts on other parameters was neutral or negative. Ellagic acid, catechin (33) and catechin gallate (34) were dominant components in both extracts (Jurić et al., 2020).

\subsection{Antibacterial and antifungal properties}

Although there are over 200 types of antibiotics and chemotherapeutics available on the world drug market today, the problem of bacterial multidrug resistance remains. One reason is the appearance and spreading of multiresistant and pan-resistant agents around the world leading to severe infections in humans and animals. The World Health Organization has declared the spreading of pan-resistant bacterial strains "pandemic of pan resistance" because these strains were found all over the world. Still, there is not one specific solution for this phenomenon. Infections caused by pan-resistant agents lead to death in more than $90 \%$ of the cases. This is why the scientists in the scientific literature call bacterial resistance to antibiotics "the plague of the $21^{\text {st }}$ century". In this context, plants are considered as sources of non-antibiotic substances with antibacterial activity, at the same time with no contribution to further increase of the resistance. Another reason for the utilization of plant extracts is their complex multicomponent nature that may be especially well suitable for interfering simultaneously with multiple targets, encompassing the possibility of low-dose administration of active agents and therefore reducing the potential undesired events, while at the same time providing prospective synergistic or additive effects. The search for new and effective antimicrobial natural products revealed that secondary metabolite isolated from plant materials possessed the antimicrobial activity against antibiotics resistant pathogens (Atef et al., 2019).

Morover, there is significant consumer demand for foods that are minimally processed and free from synthetic chemical preservatives with the perception of being "natural". As a result, the food industry is facing great challenges to produce naturally occurring food antimicrobials and antioxidants to reduce the use of synthetic chemical preservatives and still produce safe foods that are also regarded as healthy. The impact of food-borne diseases on children, the aging population, and the immunocompromised individuals, as an emerged public health problem, caused the increased interest in the utilization of plant extracts as antimicrobial agents for food preservation. The World Health Organization has defined the meaning of food-borne illness as the disease after ingestion of contaminated food or water. Food contamination can occur during any time between food production and consumption. In addition, the epidemiology of foodborne diseases indicated that the bacterial infections caused, mainly, by Salmonella enteritidis, Escherichia coli, Bacillus cereus, and Staphylococcus aureus have become increasingly resistant to empirical antimicrobial agents.

Recent studies performed by (Boroja et al., 2018) confirmed significant antibacterial activity lady's mantle aerial extracts. Enterococcus faecalis, S. typhimurium, Micrococcus lysodeikticus, and $B$. mycoides were the most sensitive examined bacterial species to the tested lady's mantle extracts, with MICs between 0.156 and $0.625 \mathrm{mg} / \mathrm{mL}$ revealing the moderate antimicrobial activity. Namely, according to (Kuete, 2010), an extract can be considered as a potent antibacterial agent with significant antibacterial activity with MICs below $0.1 \mathrm{mg} / \mathrm{mL}$, while MICs between 0.1 and 0.625 pointed to moderate activity against bacterial growth. MICs above $0.625 \mathrm{mg} / \mathrm{mL}$ referred to weak activity. On the contrary, Klebsiella pneumoniae was the most resistant bacteria in the study (MIC $=5$ and $10 \mathrm{mg} / \mathrm{mL}$ ). MICs values above $1 \mathrm{mg} / \mathrm{mL}$ for the investigated extracts were also observed for Pseudomonas aeruginosa, B. subtilis, Azotobacter chroococcum, and E. coli. As in the study ellagic acid and catechin were used as reference compounds, catechin failed to inhibit the growth of all tested bacteria at concentrations lower 
than $0.5 \mathrm{mg} / \mathrm{mL}$, while ellagic acid exhibited antibacterial potential against the same bacteria as the extracts, but with MICs being lower than those for the extracts for the majority of bacteria. The investigation of the antifungal activity against $A s-$ pergillus brasiliensis, Phialophora fastigiate, Penicillium canescens, Trichoderma viride, T. longibrachiatum, A. glaucus, Fusarium oxysporum, Alternaria alternata, Doratomyces stemonitis and yeast Candida albicans revealed weak activity of the tested extracts with MICs greater than $2.5 \mathrm{mg} / \mathrm{mL}$ (Boroja et al., 2018).

The antibacterial activity was evaluated as well, against food poisoning bacteria including two strains of Gram-positive bacteria (B. cereus and S. aureus) and two strains of Gram-negative bacteria (E. coli, and P. aeruginosa) using the disc diffusion method and determining the minimal inhibitory concentration, revealing MIC values to be greater than $1 \mathrm{mg} / \mathrm{mL}$. Generally, Gram negative bacteria such as E. coli, P. aeruginosa and $S$. enteritidis were less sensitive to the antimicrobials because of the lipopolysaccharide outer membrane of this group, which restricts diffusion of phenolic compounds. In contrast, Grampositive bacteria (S. aureus, Listeria monocytogenes, or B. cereus) are usually more susceptible to bioactive compounds of plants due to the direct interaction of the cell membrane with their lipophilic compounds (Seffo, 2020).

\subsection{Antiviral activity}

Despite a global victory over smallpox, there is still a potential danger of re-emergency of this infection, because zoonotic orthopoxviruses pathogenic for humans (vaccinia, smallpox buffalo, cowpox, and monkeypox) and their natural reservoir (various rodents) persist in many parts of Central Africa, Eurasia, and South America. In spite that vaccination is the most effective way of protection against smallpox and other orthopoxviruses, vaccines can cause adverse side effects and vaccine-induced complications. Besides, antiviral drugs, e.g. Cidofovir and Glivec, have been shown to exhibit relatively low activity against smallpox. In addition, constant mutations that characterized the viral genome, contributed to overall unsatisfactory outcomes of antiviral drug application, concurrently developing the drug resistance to the virus. The abovementioned problems necessitate the search for the development of new antiviral drugs and new antiviral compounds with different mechanisms of action. The unexpected side effects of conventional drugs and the growing phenomenon of resistance have led researchers to turn to the plant kingdom as a source of potential new antiviral drugs. The plant complexes have proved to be usually more active than their most abundant isolated compounds because of existing synergistic mechanisms. The interaction mechanisms of bioactive compounds with target molecules were investigated on the cellular and molecular level, but for detailed highlighting of the action mechanism, the molecular docking studies were conducted, as well (Denaro et al., 2020). Recently performed experiments have shown that plants exhibited significant antiviral activity, confirmed in in vitro and in vivo studies. However, the same plants can have different antiviral activity against RNA or DNA viruses, either enveloped or non-enveloped, and even against different types or strains of a virus.

In the research performed by Filippova (2017), antiviral effects of the aqueous solutions of the lady's mantle aerial parts and roots extracts were studied in vitro using a continuous cell line of kidney cells of green monkey (Vero). Orthopoxviruses vaccinia virus (VV, strain L IVP) and smallpox virus of mice (ectromelia virus, EV, strain K-1) were expanded in Vero cell culture. Antiviral activity of lady's mantle extracts was evaluated by changes in orthopoxvirus titers in Vero cell monolayer. Increasing the concentration of all studied extracts of lady's mantle led to a decrease in the titers of VV and EV and, consequently, to an increase in neutralization indices, calculated as differences between Titer of control and Titer, experimentally obtained for orthopoxviruses. In general, lady's mantle extracts suppressed the reproduction of orthopoxviruses (VV and EV) in the culture of Vero cells. Further studies should be aimed at the identification of the substance responsible for the activity.

\subsection{Other biological properties}

Apart from the activities mentioned in subsections 3.1.- 3.8, the detailed survey of the literature revealed that lady's mantle extracts exerted other biological activities. The enzyme inhibitory activities were confirmed. Namely, besides the already described significant anti-cholinesterase and antityrosinase activities, lady's mantle extracts exhibited the antiamylase activity. The presence of polyphenols such as catechin, quercetin, and luteolin-7-O- $\beta$-glucoside in the investigated extracts might be responsible for the shown activity (Jhong et al., 2015; Martinez-Gonzalez et al., 2019; Vlaisavljević et al., 2019; Yilmazer-Musa et al., 2012). The study of Pawlaczyk et al. (2009) has revealed the anticoagulant activity of lady's mantle which is traditionally used as an anti-inflammatory, carminative and antidiarrheal remedy and also against gastritis and burns in Poland. According to an in vivo study, the extract prepared from the aerial part of lady's mantle and containing polyphenolic compounds was found to stimulate synthesis and peripheral deiodination of thyroid hormones in rats which were subjected to intense cooling. (Borodin et al., 1999; Pawlaczyk et al., 2009). Lady's mantle was reported to possess inhibitory activity of pancreatic lipase, as well, shown in the study of Slanc et al. (2009).

\section{CONCLUSION}

A detailed survey of the literature regarding chemical composition and biological properties of lady's mantle (Alchemilla vulgaris L., Rosaceae) confirmed its potential medicinal significance. The recent scientific research confirmed some of lady's mantle biological properties recognized within traditional use, such as effects on wound healing and dysmenorrhea. However, a lot of work remains to be done to determine optimal treatments, doses, and formulae for the preparations obtained from this plant. In addition, data about the interactions of medicinal plants in the living system is scarce, opening the direction of future research towards the pharmacokinetics and pharmacodynamics investigation. Therefore, further investigations should be performed to provide evidence of in vivo biological effects as a prerequisite for their prospective clinical confirmation.

\section{ACKNOWLEDGMENTS}

The authors wish to send their gratitude to Serbian Ministry of Education, Science and Technological Development (Contract No. 451-03-68/2020-14/200003).

\section{REFERENCES}

Abdel-Daim, M. M., Aleya, L., El-Bialy, B. E., Abushouk, A. I., Alkahtani, S., Alarifi, S. and others (2019). The ameliorative effects of ceftriaxone and vitamin $\mathrm{E}$ against cisplatininduced nephrotoxicity, Environmental Science and Pollution Research 26(15): 15248-15254.

Amadeu, T. P., Coulomb, B., Desmouliere, A. and Costa, A. M. A. (2003). Cutaneous Wound Healing: Myofibroblastic Differentiation and in Vitro Models, The International Journal of Lower Extremity Wounds 2(2): 60-68.

Asnaashari, S., Dastmalchi, S. and Javadzadeh, Y. (2018). Gastroprotective effects of herbal medicines (roots), International Journal of Food Properties 21(1): 902-920. 
Atef, N. M., Shanab, S. M., Negm, S. I. and Abbas, Y. A. (2019). Evaluation of antimicrobial activity of some plant extracts against antibiotic susceptible and resistant bacterial strains causing wound infection, Bulletin of the National Research Centre 43(1): 144.

Bae, J.-Y., Choi, J.-S., Kang, S.-W., Lee, Y.-J., Park, J. and Kang, Y.-H. (2010). Dietary compound ellagic acid alleviates skin wrinkle and inflammation induced by UV-B irradiation: Ellagic acid and alleviation of photoageing, Experimental Dermatology 19(8): e182-e190.

Blumental, M., Busse, W., Goldberg, A., Gruenwald, J., Hall, T., Riggins, W., Rister, R., Klein, S. and Tyler, V. (1998). The complete German Commission E Monographs: Therapeutic guide to herbal medicines, $1^{\text {st }}$ edn, American Botanical Council, Austin, Texas : Boston.

Borodin, Y. I., Selyatitskaya, V. G., Obukhova, L. A., Pal'chikova, N. A., Odintsov, S. V. and Kukushkina, T. A. (1999). Effects of polyphenol compounds from Alchemilla vulgaris on morphofunctional state of thyroid gland in rats exposed to low temperature, Bulletin of Experimental Biology and Medicine 127(6): 637-639.

Boroja, T., Mihailović, V., Katanić, J., Pan, S.-P., Nikles, S., Imbimbo, P., Monti, D., Stanković, N., Stanković, M. and Bauer, R. (2018). The biological activities of roots and aerial parts of Alchemilla vulgaris L., South African Journal of Botany 116: $175-184$.

Bulduk, I., Gokce, S. and Enginar, H. (2018). Study on optimum extraction conditions for galantamine from Galanthus woronowii L. Bulbs, European Journal of Medicinal Plants 24(4): 1-12.

Carballo-Carbajal, I., Laguna, A., Romero-Giménez, J., Cuadros, T., Bové, J., Martinez-Vicente, M. and others (2019). Brain tyrosinase overexpression implicates age-dependent neuromelanin production in Parkinson's disease pathogenesis, Nature Communications 10(1): 973.

Choi, J., Park, Y.-G., Yun, M.-S. and Seol, J.-W. (2018). Effect of herbal mixture composed of Alchemilla vulgaris and Mimosa on wound healing process, Biomedicine $\mathcal{E}$ Pharmacotherapy 106: 326-332.

Denaro, M., Smeriglio, A., Barreca, D., De Francesco, C., Occhiuto, C., Milano, G. and Trombetta, D. (2020). Antiviral activity of plants and their isolated bioactive compounds: An update, Phytotherapy Research 34(4): 742-768.

Duckstein, S. M., Lotter, E. M., Meyer, U., Lindequist, U. and Stintzing, F. C. (2012). Phenolic constituents from Alchemilla vulgaris L. and Alchemilla mollis (Buser) Rothm. at different dates of harvest, Zeitschrift für Naturforschung C 67(1112): $529-540$

Ergene, B., Acikara Bahadir, Ö., Bakar, F., Saltan, G. and Nebioğlu, S. (2010). Antioxidant activity and phytochemical analysis of Alchemilla persica Rothm., Ankara Universitesi Eczacilik Fakultesi Dergisi 39(2): 145-154.

ESCOP (2003). Herbal Monograph Alchemillae herba - Alchemilla / Lady's Mantle, The Scientific Foundation for Herbal Medicinal Products, European Scientific Cooperative on Phytotherapy (ESCOP). Online series.

Evans, W. C. and Evans, D. (2009). A taxonomic approach to the study of medicinal plants and animal-derived drugs, Trease and Evans' Pharmacognosy, Elsevier, pp. 18-44.
Filippova, E. I. (2017). Antiviral activity of lady's mantle (Alchemilla vulgaris L.) extracts against orthopoxviruses, Bulletin of Experimental Biology and Medicine 163(3): 374-377.

Ghedira, K., Goetz, P. and Le Jeune, R. (2012). Alchemilla vulgaris L.: Alchémille (Rosaceae), Phytothérapie 10(4): 263266.

Gibbons, S. (2003). An overview of plant extracts as potential therapeutics, Expert Opinion on Therapeutic Patents 13(4): 489497.

Hager (1979). Handbuch der pharmazeutischen praxis, Vol. Bd. 6 of Teil $C, 1^{\text {st }}$ edn, Springer-Verlag, Berlin.

Heinrich, M., Barnes, J., Gibbons, S. and Williamson, E. (2012). Production, standardization and quality control, Fundamentals of pharmacognosy and phytotherapy, $2^{\text {nd }}$ edn, Churchill Livingstone: Elsevier.

Hou, Y., Dan, X., Babbar, M., Wei, Y., Hasselbalch, S. G. Croteau, D. L. and Bohr, V. A. (2019). Ageing as a risk factor for neurodegenerative disease, Nature Reviews Neurology 15(10): 565-581.

Ilić-Stojanović, S., Nikolić, V., Kundaković, T., Savić, I., SavićGajić, I., Jocić, E. and Nikolić, L. (2018). Thermosensitive hydrogels for modified release of ellagic acid obtained from Alchemilla vulgaris L. extract, International Journal of Polymeric Materials and Polymeric Biomaterials 67(9): 553-563.

Jhong, C.-H., Riyaphan, J., Lin, S.-H., Chia, Y.-C. and Weng, C.F. (2015). Screening alpha-glucosidase and alpha-amylase inhibitors from natural compounds by molecular docking in silico: Screening alpha-glucosidase and alpha-amylase inhibitors, BioFactors 41(4): 242-251.

Jimenez, F., Mitts, T. F., Liu, K., Wang, Y. and Hinek, A. (2006). Ellagic and tannic acids protect newly synthesized elastic fibers from premature enzymatic degradation in dermal fibroblast cultures, Journal of Investigative Dermatology 126(6): 1272-1280.

Jurić, T., Katanić Stanković, J. S., Rosić, G., Selaković, D., Joksimović, J., Mišić, D., Stanković, V. and Mihailović, V. (2020). Protective effects of Alchemilla vulgaris L. extracts against cisplatin-induced toxicological alterations in rats, South African Journal of Botany 128: 141-151.

Kim, Y.-J. and Uyama, H. (2005). Tyrosinase inhibitors from natural and synthetic sources: structure, inhibition mechanism and perspective for the future, Cellular and Molecular Life Sciences 62(15): 1707-1723.

Krivokuća, M., Niketić, M., Milenković, M., Golić, N., Masia, C., Scaltrito, M. M., Sisto, F. and Kundaković, T. (2015). Anti-Helicobacter pylori activity of four Alchemilla species (Rosaceae), Natural Product Communications 10(8): 1934578X1501000.

Kuete, V. (2010). Potential of Cameroonian plants and derived products against microbial infections: A review, Planta Medica 76(14): 1479-1491.

Lalkovicová, M. and Danielisová, V. (2016). Neuroprotection and antioxidants, Neural Regeneration Research 11(6): 0.

Lanas, A. and Chan, F. K. L. (2017). Peptic ulcer disease, The Lancet 390(10094): 613-624.

Lee, S. Y., Baek, N. and Nam, T.-g. (2016). Natural, semisynthetic and synthetic tyrosinase inhibitors, Journal of Enzyme Inhibition and Medicinal Chemistry 31(1): 1-13. 
Malfertheiner, P., Chan, F. and McColl, K. (2009). Peptic ulcer disease., The Lancet 374(9699)): 1449-1461.

Mandrone, M., Coqueiro, A., Poli, F., Antognoni, F. and Choi, Y. (2018). Identification of a collagenase-inhibiting flavonoid from Alchemilla vulgaris Using NMR-based metabolomics, Planta Medica 84(12/13): 941-946.

Martinez-Gonzalez, A., Díaz-Sánchez, G., de la Rosa, L. Bustos-Jaimes, I. and Alvarez-Parrilla, E. (2019). Inhibition of $\alpha$-amylase by flavonoids: structure activity relationship (SAR), Spectrochimica Acta Part A: Molecular and Biomolecular Spectroscopy 206: 437-447.

Micov, A. and Pecikoza, U. (2020). Anti-dementia medications: Fighting a losing battle?, Arhiv za farmaciju 70(2): 55-68.

Neagu, E., Paun, G., Albu, C. and Radu, G.-L. (2015). Assessment of acetylcholinesterase and tyrosinase inhibitory and antioxidant activity of Alchemilla vulgaris and Filipendula ulmaria extracts, Journal of the Taiwan Institute of Chemical Engineers 52: 1-6.

Ojha, S., Venkataraman, B., Kurdi, A., Mahgoub, E., Sadek, B. and Rajesh, M. (2016). Plant-derived agents for counteracting cisplatin-induced nephrotoxicity, Oxidative Medicine and Cellular Longevity 2016: 1-27.

Oun, R., Moussa, Y. E. and Wheate, N. J. (2018). The side effects of platinum-based chemotherapy drugs: a review for chemists, Dalton Transactions 47(19): 6645-6653.

Özbilgin, S., Özbek, H., Kirmizi, N., Öz, B., Kurtul, E., Özrenk, B., Saltan Işcan, G. and Bahadir Acikara, O. (2019). Evaluation of the antidiabetic activity of Alchemilla persica Rothm. in mice with diabetes induced by Alloxan, Turkish Journal of Pharmaceutical Sciences 16(3): 261-264.

Pawlaczyk, I., Czerchawski, L., Pilecki, W., Lamer-Zarawska, E. and Gancarz, R. (2009). Polyphenolic-polysaccharide compounds from selected medicinal plants of Asteraceae and Rosaceae families: Chemical characterization and blood anticoagulant activity, Carbohydrate Polymers 77(3): 568-575.

Petrović, S. (2019). Herbal and traditional Herbal Medicinal Products, EU Herbal monographs and EU list, Arhiv za farmaciju 69(4): 221-269.

Seffo, S. (2020). Antimicrobial activity of crude extracts of alchemilla vulgaris and Salvia officinalis L. against some bacterial strains causing food poisoning diseases, 8(3): 6 .

Shilova, I. V., Suslov, N. I., Samylina, I. A., Baeva, V. M., Lazareva, N. B. and Mazin, E. V. (2020). Neuroprotective properties of common lady's mantle infusion, Pharmaceutical Chemistry Journal 53(11): 1059-1062.

Si, Y.-X., Yin, S.-J., Oh, S., Wang, Z.-J., Ye, S., Yan, L., Yang, J.M., Park, Y.-D., Lee, J. and Qian, G.-Y. (2012). An integrated study of tyrosinase inhibition by rutin: progress using a computational simulation, Journal of Biomolecular Structure and Dynamics 29(5): 999-1012.

Singer, A. J. and Clark, R. A. (1999). Cutaneous wound healing New England Journal of Medicine 341(10): 738-746.

Slanc, P., Doljak, B., Kreft, S., Lunder, M., Janeš, D. and Štrukelj, B. (2009). Screening of selected food and medicinal plant extracts for pancreatic lipase inhibition: Inhibition of pancreatic lipase by plant extracts, Phytotherapy Research 23(6): 874877.
Tadić, V., Žugić, A. and I., A. (2014). Multi-target herbal preparation, in R. Edward (ed.), Supercritical CO2 extractions, Polish Foundations of the Opportunities Industralization Centers „OIC Poland“, Lublin, Poland, pp. 99-121.

Tasić-Kostov, M., Arsić, I., Pavlović, D., Stojanović, S., Najman, S., Naumović, S. and Tadić, V. (2019). Towards a modern approach to traditional use: in vitro and in vivo evaluation of Alchemilla vulgaris L. gel wound healing potential, Journal of Ethnopharmacology 238: 111789.

Tucakov, J. (1997). Lečenje Biljem, Rad, Beograd.

Valcheva-Kuzmanova, S., Denev, P., Eftimov, M., Georgieva, A., Kuzmanova, V., Kuzmanov, A., Kuzmanov, K. and Tzaneva, M. (2019). Protective effects of Aronia melanocarpa juices either alone or combined with extracts from Rosa canina or Alchemilla vulgaris in a rat model of indomethacininduced gastric ulcers, Food and Chemical Toxicology 132: 110739 .

Vlaisavljević, S., Jelača, S., Zengin, G., Mimica-Dukić, N., Berežni, S., Miljić, M. and Stevanović, Z. D. (2019). Alchemilla vulgaris agg. (lady's mantle) from central Balkan: antioxidant, anticancer and enzyme inhibition properties, RSC Advances 9(64): 37474-37483.

Yilmazer-Musa, M., Griffith, A. M., Michels, A. J., Schneider, E. and Frei, B. (2012). Grape seed and tea extracts and catechin 3-gallates are potent inhibitors of $\alpha$-amylase and $\alpha$-glucosidase activity, Journal of Agricultural and Food Chemistry 60(36): 8924-8929.

Žižović, I., Arsić, I., Tadić, V., Mišić, D., Petrović, S., Jovanović, S. and et al. (2016). Bioactive semisolid and solid phytopreparations, Patent RS 55130 B1. 